\title{
ANSI / FM Approvals 2510 flood abatement equipment test standard
}

\author{
Frédéric Kravetz ${ }^{1, a}$ \\ ${ }^{1}$ FM Approvals France, 8 cours du Triangle 92937 La Défense Cedex, France
}

\begin{abstract}
Natural hazards, including flooding, continue to be the leading cause of commercial and industrial property damage worldwide. Until recently, there has been a limited amount of readily available guidance on choosing flood abatement protection. FM Approvals, a division of FM Global, one of the world's largest business property insurers, working together with the Association of State Floodplain Managers and the US Army Corps of Engineers have developed a National Flood Barrier Test Program after recognizing the urgent demand for reliable flood abatement products to mitigate potential losses. This lead to the ANSI/ FM2510 flood abatement equipment standard.
\end{abstract}

\section{Flood risk and facts}

Flooding is one of the most complex property risks facing property owners and insurers alike. Ongoing analysis by the FM Approvals parent company, FM Global, shows that a property located within a published flood zone is five to seven times more likely to suffer a flood loss than to suffer an equivalent loss due to fire or explosion. In addition, the average flood loss is about 1.5 times as great as the average fire loss.

As England emerges from one of its wettest winter on record, a study published in the journal Nature Climate Change predicts that average annual flood damage losses in Europe will increase to $€ 23$ billion by 2050 , compared to the $€ 4.9$ billion seen between 2000 and 2012 [1].

In 2011, Bangkok flooding reportedly costed $€ 40$ billion damages [2], more than 14000 companies [3] have been touched. The supply chain upstream companies have had an international repercussion because of all electronic components manufacturing used for automotive and hard disk drives. This latter shortage lasted more than one year to be compensated.

FM Global studies show that flooding costs companies an average of $€ 2$ to $€ 3$ billion in losses annually worldwide-making it the most costly natural hazard globally.

For facilities in the planning stages, the simple solution to flood risk is to locate the facility outside of the high-and moderate-hazard flood zone and levee/floodwall failure inundation areas, and design the site to ensure all stormwater drainage systems are adequate. In some cases,

${ }^{\mathrm{a}}$ Corresponding author: frederic.kravetz@fmapprovals.com flood risk can be reduced by using fill to elevate the building site above the 500-year flood level.

However, approximately one in 10 industrial facilities is located within a flood zone. Facilities at risk for flooding must prepare well in advance in order to keep water out of critical buildings and limit resulting damages.

\section{Proactive flood protection is the right choice for flood-prone properties}

Climate change science is complex, and researchers at FM Global work with scientists around the world to continually evaluate the potential for natural catastrophes, develop innovative methods and tools to predict and prevent property damage, and provide practical engineering solutions.

Among the physical preparations that firms can take to reduce the impact of flood events include:

- permanent protection for electrical, computer and telecommunications equipment

- relocation of high value stock and equipment

- permanent or temporary barriers to protect against flood waters

Many companies from all around the world are installing flood abatement systems and equipment to proactively guard against future flood losses, particularly following "Superstorm" Sandy, which devastated large portions of the United States Northeastern Seaboard in October 2012. Sandy caused an estimated $€ 70$ billion in total losses and $€ 35$ billion in insured losses. 


\section{FM Approved flood protection}

FM Approvals was set up to test and approve products that are then used in property that FM Global insures.

FM approvals standards are widely used and recognized all over the world.

Most specifically regarding Europe, the SMARTeST project (Smart Resilient Technologies, Systems and Tools) founded under the European Union's FP7 Research Program, was conceived in order to address many of the issues of integration of flood resilience technology into the overall approach to flood risk management. It's directly referencing the FM Approvals standard 2510, highlighting its value for assessing flood mitigation products.

FM Approvals is an accredited, third-party testing and certification organization and is also a Notified Body and Technical Assessment Body (EOTA, European Organisation for Technical Assessment) designated under the Construction Products Regulation. It's a standards setting and product certification organization with offices in Europe, Asia and the Americas.

FM Approvals, directly and in partnership with other testing organizations, evaluates many different types of loss prevention products, including flood protection products. It is the only organization that tests individual components and materials associated with flood mitigation products, as well as subjects products to fullscale simulated riverine flood tests.

\section{The ANSI/FM2510 standard}

FM Approval Standard ANSI/FM2510 evaluates not only the performance of the flood mitigation product in realistic flood conditions but also the components and materials that comprise the product.

The standard is covering for 4 types of flood abatement equipment:

- Opening barriers

- Perimeter barriers

- Backwater valves

- Flood mitigation pumps

More specifically, for barriers there are 2 types of requirements: general requirements and performance testing requirements.
In the general requirements part of the standard, we recognize that any product is only as strong as its weakest link. Therefore we subject flood barrier components and materials to several tests:

- Pressure retaining components are subject to hydrostatic strength and leakage testing.

- Moving parts are subject to durability - cycle testing.

- Gaskets are subject to tensile and compression tests.

- Certain materials are subject to abrasion resistance.

- Environmental and corrosion testing.

All to ensure no one component is going break down and compromise the entire system.

\subsection{Perimeter barriers}

Performance testing of perimeter barriers is designed to simulate actual riverine flooding conditions on full-scale barriers. Tests include hydrostatic loading and incidental wave; wave-induced hydrodynamic loading; overtopping; debris impact; and flowing water current test (ref to Table 1.).

The water test protocol is an extensive test program in which the barrier is set up in the skewed u-shape, as shown in Figure 1.

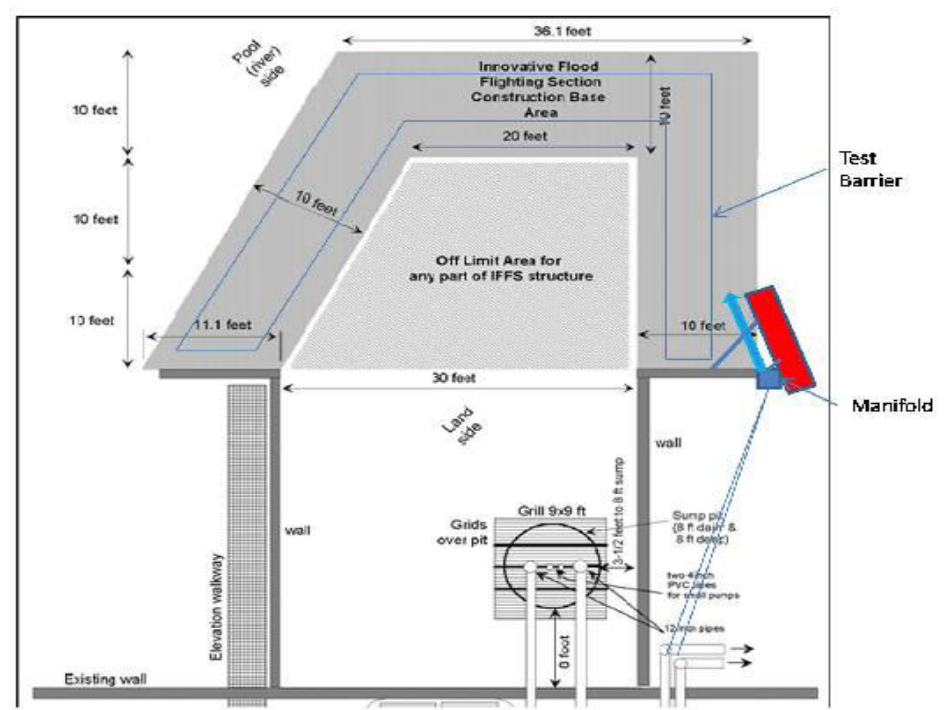

Fig 1. Perimeter barriers test set-up

It includes static water testing at various depths of water over an extended period of time. It's followed by dynamic wave testing in which the barrier is hit with small 5 to $10 \mathrm{~cm}$ waves, medium 15 to $20 \mathrm{~cm}$ waves, and large 25 to $30 \mathrm{~cm}$ waves for various periods of time. 
FLOODrisk 2016 - $3^{\text {rd }}$ European Conference on Flood Risk Management

\begin{tabular}{|c|c|c|c|}
\hline \multirow{2}{*}{ Test Description } & \multicolumn{2}{|c|}{ Water Condition(s) } & \multirow{2}{*}{ Duration } \\
\hline & Water Depth* & Other & \\
\hline Deployment & N/A & N/A & $\begin{array}{l}\text { Per Manufacturer's } \\
\text { Specification }\end{array}$ \\
\hline \multirow{3}{*}{ Hydrostatic Load } & $1.0 \mathrm{ft}(0.30 \mathrm{~m})$ & N/A & $22 \mathrm{hr}$ \\
\hline & $2.0 \mathrm{ft}(0.61 \mathrm{~m})$ & N/A & $22 \mathrm{hr}$ \\
\hline & 100 percent $\mathrm{x} \mathrm{h}$ & $\mathrm{N} / \mathrm{A}$ & $22 \mathrm{hr}$ \\
\hline \multirow{6}{*}{$\begin{array}{l}\text { Wave-Induced } \\
\text { Hydrodynamic } \\
\text { Load }\end{array}$} & 66.7 percent $\mathrm{x} h$ & low waves $2-3$ in $(51-76 \mathrm{~mm})$ & $7 \mathrm{hr}$ \\
\hline & 66.7 percent $\mathrm{x} h$ & medium waves $6-8$ in $(152-203 \mathrm{~mm})$ & $10 \mathrm{~min}$ (3 times) \\
\hline & 66.7 percent $\mathrm{x} h$ & high waves $10-12$ in $(254-305 \mathrm{~mm})$ & $10 \mathrm{~min}$ \\
\hline & 80 percent $\mathrm{xh}$ & low waves $2-3$ in $(51-76 \mathrm{~mm})$ & $1 \mathrm{hr}(\min )-7 \mathrm{hr}(\max )$ \\
\hline & 80 percent $\mathrm{xh}$ & medium waves 6-8 in (152-203 mm) & $10 \min (3$ times $)$ \\
\hline & 80 percent $\mathrm{xh}$ & high waves $10-12$ in $(254-305 \mathrm{~mm})$ & $10 \mathrm{~min}$ \\
\hline Overtopping & $\geq 1$ in $(25 \mathrm{~mm})$ overflow & N/A & $1 \mathrm{hr}$ \\
\hline \multirow{2}{*}{ Debris Impact } & 66.7 percent $\mathrm{x} h$ & $\begin{array}{c}12 \text { in }(30 \mathrm{~cm}) \text { diameter log } \\
610 \mathrm{lb}(277 \mathrm{~kg}) \text { weight } \\
\text { at } 7 \mathrm{ft} / \mathrm{s}(2.13 \mathrm{~m} / \mathrm{s})\end{array}$ & N/A \\
\hline & 66.7 percent $\mathrm{x} h$ & $\begin{array}{c}17 \text { in }(43 \mathrm{~cm}) \text { diameter log } \\
790 \mathrm{lb}(358 \mathrm{~kg}) \text { weight } \\
7 \mathrm{ft} / \mathrm{s}(2.13 \mathrm{~m} / \mathrm{s})\end{array}$ & N/A \\
\hline Current & 66.7 percent $\mathrm{x} \mathrm{h}$ & $7 \mathrm{ft} / \mathrm{s}(2.13 \mathrm{~m} / \mathrm{s})$ current & $1 \mathrm{hr}$ \\
\hline $\begin{array}{c}\text { Post Hydrostatic } \\
\text { Load }\end{array}$ & 100 percent $\mathrm{x} \mathrm{h}$ & N/A & $1 \mathrm{hr}(\min )-22 \mathrm{hr}(\max )$ \\
\hline
\end{tabular}

Table 1. Perimeter barriers tests

Perimeter barriers include rapidly deployable walls and inflatable tubes that can withstand riverine flooding.

Performance tests for opening barriers, backwater valves and flood mitigation pumps also include simulated realworld conditions.

\subsection{Opening barriers}

For the opening barriers, after completion of the hydrostatic test the test basin is drained of water, the barrier is disassembled and then redeployed. It's then subjected to the dynamic impact load test. The test consists of hitting the barrier with a 600 Joule force (Fig 2.).

The force is created by attaching a $150 \mathrm{Kg} \log$ to a pendulum arm and raising it $1.2 \mathrm{~m}$ above the point of impact. This is then followed by another hydrostatic test to ensure the impacts had no ramifications on the barrier's ability to hold water.

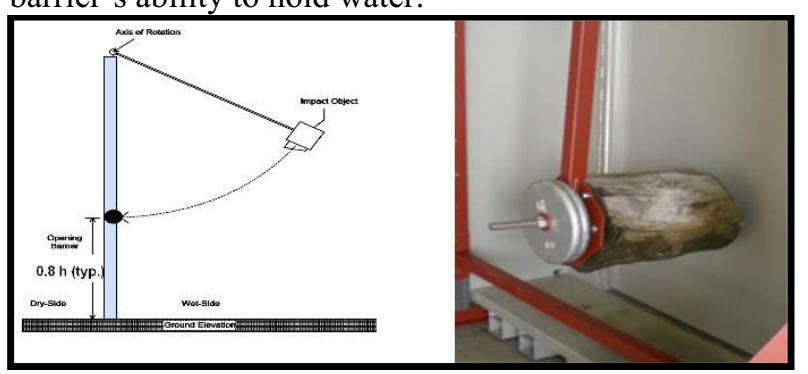

Fig 2. Impact test set-up

Opening barriers include manual or automatically deployable metal panels to prevent flood water from entering doorways and other openings.

Opening barriers typical test program is detailed below:

\begin{tabular}{|c|c|c|}
\hline Test Description & Condition ${ }^{*}$ & Duration \\
\hline Deployment & N/A & Per Manufacturer's Specifications \\
\hline Hydrostatic Load & 100 percent $\mathrm{x} h \pm 0.25$ in $(0.6 \mathrm{~cm})$ & $22 \mathrm{hr}$ \\
\hline Redeploy & Disassemble and redeploy & Per Manufacturer's Specifications \\
\hline Dynamic Impact Load & Impact at weakest point of barrier & N/A \\
\hline Post Hydrostatic Load & 100 percent $x \mathrm{~h} \pm 0.25$ in $(0.6 \mathrm{~cm})$ & $1 \mathrm{hr}$ \\
\hline Redeploy & Disassemble and redeploy & Per Manufacturer's Specifications \\
\hline Dynamic Impact Load & $\begin{array}{c}\text { Impact at the barrier connection to the supporting } \\
\text { structure }\end{array}$ & N/A \\
\hline Post Hydrostatic Load & 100 percent $x \mathrm{~h} \pm 0.25$ in $(0.6 \mathrm{~cm})$ & $1 \mathrm{hr}$ \\
\hline
\end{tabular}

Table 2. Opening barriers tests 


\subsection{Backwater valves}

The backwater valves are an important part of the reliability of the flood abatement system. Indeed, even if the water is controlled aboveground, it could come back from the underground through the sewage system.

A backwater valve shall comply with dimensional requirements and material quality.

Some key parameters that must be controlled are:

- The free opening is tested with a cylinder which can pass through the valve.

- The tightness is tested with a backpressure. The maximum water leakage allowed after 10 minutes under pressure is summarized here below:

\begin{tabular}{|c|c|}
\hline $\begin{array}{c}\text { Nominal Size, } \\
\text { Inches }\end{array}$ & $\begin{array}{c}\text { Volume of Collected Water, } \\
\text { Fl oz }(\boldsymbol{m L})\end{array}$ \\
\hline 1.5 & $5.5(163)$ \\
\hline 2 & $9.5(281)$ \\
\hline 3 & $21.5(636)$ \\
\hline 4 & $38.5(1139)$ \\
\hline 6 & $87.0(2573)$ \\
\hline 8 & $153.0(4525)$ \\
\hline
\end{tabular}

\subsection{Flood mitigation pumps}

Since the flood barriers are never considered as $100 \%$ tight, it's in most cases necessary to use flood mitigation pumps to remove the water which would leak through the barriers.

These pumps, compared to fire pumps, must be able to run a very long time and with a very dirty water. That's why specific tests have been developed in order to check the reliability of these pumps.

A sample pump, with no power, shall be capable of passing a stainless steel ball from the discharge of the pump to the water inlet. The size of the stainless stain ball must be equal to, or greater then, the clearance specifications listed by the manufacturer.

Of course, the pump performance is tested and the curve recorded.

The pump shall be capable of continuous operation for 336 hours at its rated capacity. It's therefore tested for 336 hours and no loose parts, distortion, overheating, or degradation of performance must be noticed.

Some other tests are performed to ensure the reliability: Hydrostatic Strength, On/Off Switch Durability (1000 time Cycling), Voltage Variation, Dielectric Withstand.

\subsection{Manufacturer responsibilities:}

A quality control program is required to assure that subsequent production of flood mitigation equipment systems produced by the manufacturer at an authorized location shall present the same quality and reliability as the specific flood mitigation equipment system examined.

The manufacturer or assigned representative shall perform a documented system acceptance check and operational test in accordance with the manufacturers "Design, Installation, Operation and Maintenance Manual". A copy of the results shall be kept on file and with the owner of the flood mitigation equipment system. Appropriate training shall be provided to the end-user.

\section{Loss prevention and insurance}

Flood risk is typically a challenge for insurance companies not only because it is one of those natural disasters that we know is going to happen but also due to its aggregate component. It means that a flood disaster will touch a lot of facilities within a single event.

FM Global loss history studies show that well-prepared organizations have significantly less damage and resume operations sooner than those unprepared.

FM Approved products are recommended by FM Global as part of a multi-point flood preparedness plan that includes a tested flood emergency response plan (FERP) plus temporary or permanent protection.

The first obvious advantage for companies to choose FM Approved equipment is to help them make well-informed decisions about which products and services on the market will best reduce property risk and help make businesses more resilient.

They can be sure that the perimeter barriers will, for example, withstand impacts or waves with a controlled leakage, having been tested in "real life conditions".

Second advantage is of course to potentially have better insurance terms and conditions. Underwriting impact will depend on a lot of other factors but, relying on approved products/systems to mitigate flood losses would be a consideration.

For manufacturers of flood mitigation products and systems, the FM Approvals certification mark signifies to the marketplace that the FM Approved product will meet or exceed expectations in critical flood control situations.

The majority of loss is preventable. The ability for FM Global engineers to assess the risk and propose costeffective property loss prevention solutions, including FM Approved flood protection products, is one of the key differentiators to FM Global unique approach to commercial property insurance. 


\section{References}

FM Approvals, 1151 Boston-Providence Turnpike, Norwood Massachusetts 02062

ANSI / FM Approvals Standard 2510 - Approval standard for flood abatement equipment

ANSI: American National Standard Institute

SMARTest D2.3 Final: July 2013 Flood Resilience

Technologies

[1] Nature Climate Change 4, 264-268 (2014)

http://www.nature.com/nclimate/journal/v4/n4/full/nclim ate2124.html

[2] Lloyd's case study

http://www.lloyds.com/ /media/files/news\%20and\%20in sight/global\%20underinsurance $\% 20$ report/case $\% 20$ studie s/thailand\%20flooding.pdf

World Bank estimation, December 13, 2011

http://www.worldbank.org/en/news/feature/2011/12/13/w orld-bank-supports-thailands-post-floods-recovery-effort

[3] THAILAND: Bangkok Braces for Month of Floods by Marwaan Macan-Markar (bangkok)

Tuesday, October 25, 2011

Inter Press Service 